\title{
Encapsulation of Three Different Crude Extracts Rich in Triterpenes in a Biocompatible Polymer and their Evaluation in vitro for further Applications as Anti-inflammatory and/or Anti-tumour Alternative Therapeutic Agents
}

\author{
MARIUS BIRIS ${ }^{1 \#}$, ADRIAN GLUHOVSCHI ${ }^{1 \#}$, MADALINA BORUGA ${ }^{1 *}$, VOICHITA LAZUREANU1*, IREN MOZA ${ }^{2}$, OVIDIU BORUGA \\ BRIGITHA VLAICU', MARIOARA POENARU ${ }^{1}$ \\ ${ }^{1}$ Victor Babes University of Medicine and Pharmacy Timisoara, Faculty of Medicine, 2 Eftime Murgu Sq., 300041, Timisoara, \\ Romania \\ 2Victor Babes University of Medicine and Pharmacy Timisoara, Faculty of Pharmacy, 2 Eftime Murgu Sq., 300041, Timisoara, \\ Romania
}

\begin{abstract}
Medicinal plants continue to be of real interest to researchers in interdisciplinary fields such as chemistry, pharmacy, medicine. Due to the metabolites in which it abounds, the plant material can successfully represent both a prophylactic and curative treatment. At present, countless studies, both in vitro and in vivo, are conducted to elucidate the pharmacological effects and establish the mechanisms involved. The actual experiment was purposed to evaluate the activity of raw birch bark, apple pomace and olive leaves extracts rich in triterpenes, formulated as PLGA nanoparticles, on normal/healthy different cell lines immortalized and of primary origin, such as keratinocytes, dermal fibroblasts, and gingival fibroblasts.
\end{abstract}

Keywords: triterpenes, PLGA copolymer, keratinocytes, fibroblasts, viability

In the last decade, the attempt to find new compounds with anti-inflammatory and anti-tumour activity was based on the material derived from plant kingdom. Currently $60 \%$ of utilized anti-malignant tumour compounds are obtained somehow from nature (plants, seas and oceans) [1]. Procedures relating to authenticity, safety in the growth and development of plant material in a favourable environment (e.g. unpolluted), identification of possible contaminants, and processing of extracts are part of main factors which contributes to the content of effective active principles in a final product to be tested [2,3] .

A disequilibrium regarding formation/elimination of ROS leads to formation of oxidative stress, which represents the main reason of the occurrence of various diseases as cancer, gynaecological diseases (particularly endometriosis), PCOS, menstruation disturbances, diabetes, atherosclerosis, etc. [4,5]

On the other hand some data issues that poor oral health along with various oral inflammatory diseases participate in the initiation/progression stages of some disorders like: diabetes atherosclerosis, rheumatoid arthritis and others with the need of application of modern techniques to solve the problems $[6,7]$.

The class of pentacyclic triterpenes are well-known secondary plant metabolites, with a significant number of compounds obtained after the cyclization process of squalene [8]. Different plant type are known for triterpenes content, such as mistletoe, olive, rosemary but a significant amount of triterpenes was found in the outer birch bark which seems to contain an important percentage of betulin [9]. Other compounds from this class - betulinic, ursolic, oleanolic acids - can be identified in small amounts compared to betulin in: Malus domestica Mill. (ursolic acid predominant), Viscum album L., Olea europaea L. (oleanolic acid predominant), Syzygium aromaticum L., Thymus vulgaris L. etc [10]. This type of plant extract can be utilized as study material for different pharmaceutical formulations developed for the prevention and treatment of inflammatory and / or carcinogenic pathologies. Lupeol is another bioactive molecule which seems to act as skinactivating compound with local anti-inflammatory and chemopreventive potential that reduces processes such as irritation, inflammation and degradation [11]. Nevertheless, the utilization of natural compounds has been restricted based on low stability related to various factors light, $\mathrm{pH}$, temperature conditions, etc. and low solubility which they prove. An alternative, to correct these shortcomings, is to encapsulate them in biocompatible polymers which provides both protection and preservation of biological properties [12].

This research was realized in order to observe the behaviour of some healthy cells in the presence of raw birch bark, apple pomace and olive leaves extracts, formulated as Poly Lactic-co-Glycolic Acid (PLGA) nanoparticles. These plants are known for triterpenes rich content and the study is purported in order to utilize the data obtained in assessing the potential of this type formulations under conditions such as inflammation and the malignant tumour environment.

\section{Experimental part \\ Materials and methods}

The solvents, standards and other reagents used in the experiments were acquired from Merck and Sigma-Aldrich (Germany).

The raw material, outer birch bark was collected from Western Romania, the mountains of Semenic, dried apple pomace was obtained from fruits purchased from local producers from the Caras-Severin County and olive leaves were collected from Ksamil Southern Albania. The crude extracts were obtained by maceration: $25 \mathrm{~g}$ of dried material were extracted with $100 \mathrm{~mL}$ ethanol $95 \%$, at room 
temperature, $250 \mathrm{rpm}, 24 \mathrm{~h}$ in an orbital shaker (Incubator Environmental Shaker ES-20/60). Then, the solutions were filtered and the solvent was removed with a rotaryevaporator, the solid mass obtained was dried until reaching a constant mass and finally recrystallized with ethanol and preserved at $-20^{\circ} \mathrm{C}$. Then the crude extracts (BEM-birch bark extract maceration; APEM-apple pomace extract maceration and OLEM-olive leaves extract maceration) were subjected to encapsulation and testing.

Encapsulated extracts were obtained by an emulsionevaporation method described previous in the scientific literature $[12,13]$ with minor modifications: (a) first emulsion was obtained by the addition of OP (organic phase) into the AP (aqueous phase) during 5 min then homogenized; (b) subsequent the emulsion was added to another AP and introduced in an orbital shaker, away from light for 24 hours ( $350 \mathrm{rpm}$, room temperature) and (c) the reaction mass was sonicated at cold, for half an hour. Finally, solvents were evaporated and samples were lyophilized and store at $-20^{\circ} \mathrm{C}$ until the beginning of the experiments. Organic phase was composed of $100 \mathrm{mg}$ of PLGA in $5 \mathrm{~mL}$ dichloromethane and $10 \mathrm{~mL}$ of the ethanolic extract and aqueous phase was composed of PVA in pure water. Dynamic light scattering was used for measurement of particles size and polydispersity index, and Zeta potential results were obtained with an electrophoretic light scattering device at room temperature. All the measurements were realized in triplicate.

The cells pursued in the current experiments were human immortalized keratinocytes, human dermal fibroblasts and human gingival fibroblasts which were acquired from ATCC, in the form of frozen samples. All the specific reagents necessary for the growth, evaluation and testing of cells in optimal conditions - medium (DMEM, FBM, DME:F12); kit - Keratinocyte Growth Kit; solutions FBS, PBS, EDTA, trypsin, hydrocortisone, antibiotics specific mixture, Trypan and Alamar blue were bought from Merck, Sigma Aldrich and ATCC.

Different concentrations of samples $(0.1,0.5,10,15$ and $100 \mu \mathrm{g} / \mathrm{ml}$ ) have been added to the cellular environment and evaluated over one day (at least three time periods) the cell behaviour and their viability at the end of the period (after $24 \mathrm{~h}$ ).

The Alamar blue test utilized for the evaluation of the number of viable cells was performed as described in the literature [14].

\section{Statistical analysis}

All the data obtained in the experiments were processed with the program GraphPad Prism 7.04 and the establishment of statistically significant differences was made in the software of this program with 1way ANOVA and Tukey's multiple comparisons tests.

\section{Results and discussions}

Particle size is an important parameter in the biomedical use of nanoparticles. In this study, the polydispersity index was determined along with the particle size. As can be seen in the table 1, the index values significantly differs between control nanoparticles and those loaded with extracts. DLS results revealed that the mean diameter of

\begin{tabular}{|c|c|c|c|}
\hline \multirow[t]{2}{*}{ Sample } & \multicolumn{2}{|c|}{ Particle size (nm) } & \multirow{2}{*}{$\begin{array}{c}\text { Zeta potential } \\
(\mathrm{mV}) \text { Average } \\
\pm \mathrm{SE}\end{array}$} \\
\hline & Average $\pm \mathrm{SE}$ & $\begin{array}{c}\text { Polydispersity } \\
\text { index } \pm \mathrm{SE}\end{array}$ & \\
\hline Blank BP & $176.8 \pm 0.3$ & $0.21 \pm 0.01$ & $\mathrm{St}_{5}$ \\
\hline ВEM BP & $216 \pm 19.2$ & $0.32 \pm 0.01$ & $-31.4 \pm 1.1$ \\
\hline APEM BP & $237 \pm 23.6$ & $0.41 \pm 0.03$ & $-32.2 \pm 4.3$ \\
\hline OLEM BP & $264 \pm 22.8$ & $0.37 \pm 0.01$ & $-28.9 \pm 1.7$ \\
\hline
\end{tabular}

biopolymer samples were between 216-264 nm with polydispersity index between $0.32-0.41$. The zeta potential values were negative, between - 28.9 and - $32 \mathrm{mV}$.

The solutions prepared for evaluation - different concentrations of Poly Lactic-co-Glycolic Acid biocompatible formulations of BEM, APEM and OLEM extracts obtained by emulsion-evaporation method - are safe at doses below $15 \mu \mathrm{g} / \mathrm{mL}$ and presented a cytotoxic effect against normal cells, keratinocytes and fibroblasts, only at the highest tested concentration. The activity on these cells was observed by microscopy. Crude extract stimulation cause some various transformations in cells shape. As can be observed in the figures 1-3 no significant toxicity was exerted by the formulations with biocompatible polymer on cell viability.

In vitro assessments are essential in order to elucidate the behaviour of the various compounds as potential candidates in the treatment of various pathologies involving inflammatory and tumoral processes. Nevertheless, in silico, in vitro, ex vivo and in vivo studies need to be developed and correlated to get a complete picture of a certain direction regarding the pathology approach and treatment. Animal models are precise replies of some clinical regards and are important in elucidating certain mechanisms of action but they cannot be carried out, particularly for reasons of ethics and bioethics, without prior studies on cell cultures for example $[15,16]$.
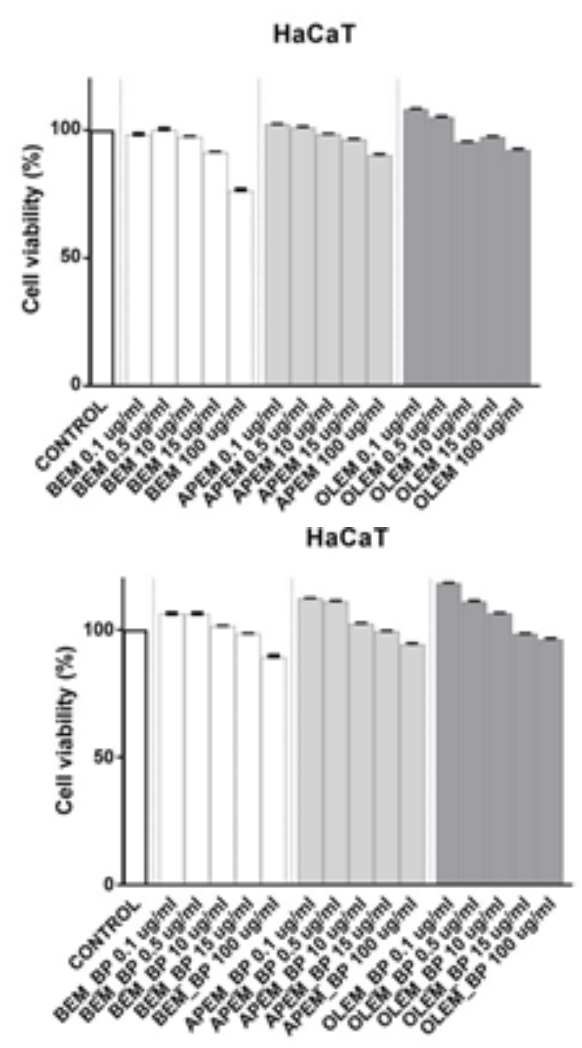

Fig. 1. Percentage of keratinocytes cell viability after stimulation with birch bark, apple pomace and olive leaves crude extract and biopolymer formulations at different concentrations

\section{Table 1}

AVERAGE PARTICLE SIZE, POLYDISPERSITY INDEX AND ZETA POTENTIAL OF POLY LACTIC-CO-

GLYCOLIC ACID BIOCOMPATIBLE FORMULATIONS OF BIRCH BARK, APPLE POMACE AND OLIVE LEAVES CRUDE EXTRACTS 

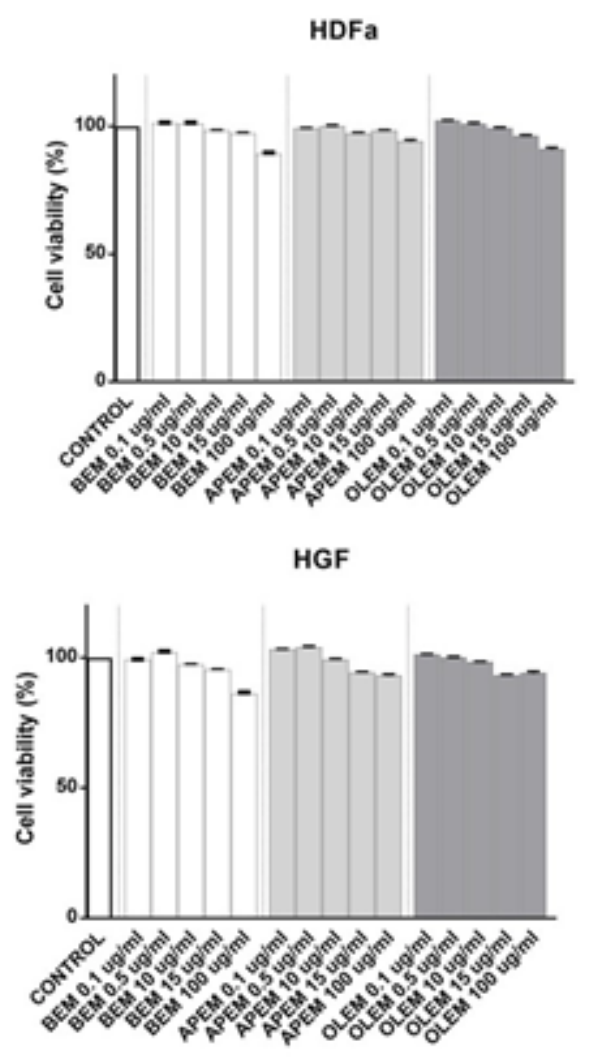

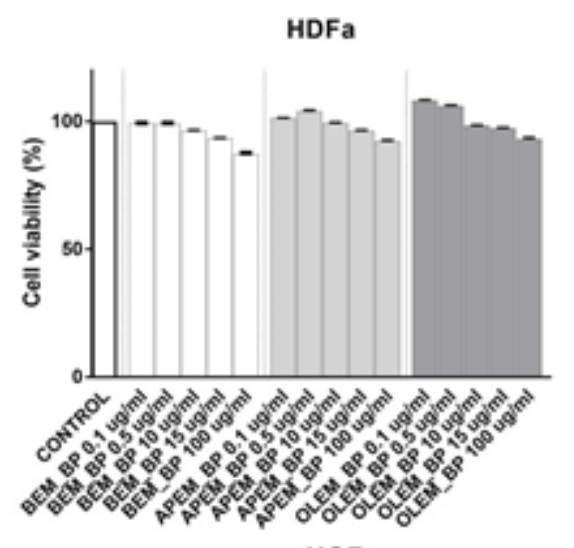

HGF

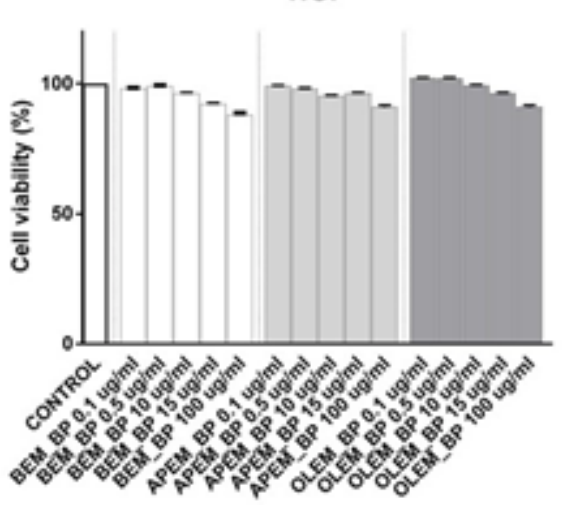

Fig. 2. Percentage of dermal fibroblasts cell viability after stimulation with birch bark, apple pomace and olive leaves crude extract and biopolymer formulations at different concentrations

\section{Conclusions}

The originality of this research consists in the elucidation of behaviour of different healthy human cells, both immortalized and primary, in the presence of biopolymer formulations by using PLGA along with crude birch bark, apple pomace and olive leaves ethanolic extract, in terms of viability. These cells type are commonly used in in vitro studies conducted to testnew compounds with potentially anti-inflammatory and carcinogenic potential and the assessment of normal cell toxicity is a key step in the study of new curative compounds.

\footnotetext{
Abbreviations list

AP - aqueous phase

APEM - apple pomace extract maceration

ATCC - American Type Cell Collection

BEM - birch bark extract maceration

DLS - Dynamic light scattering

DME:F12 - and Dulbecco's Modified Eagle's Medium/Ham's Nutrient

Mixture F-12

DMEM - Dermal Cell Basal Medium

EDTA - ethylene diamine tetraacetic acid

FBM - Fibroblast Basal Medium

FBS - fetal bovine serum

OLEM - olive leaves extract maceration

$O P$ - organic phase

PCOS -npolycystic ovarian syndrome

PLGA - Poly Lactic-co-Glycolic Acid

PSB - phosphate saline buffer

PVA - Polyvinyl alcohol

ROS - reactive oxygen species
}

\section{References}

1. CRAGG, G.M., NEWMAN, D.J .J Ethnopharmacol. 100, 2005, p. 72. 2. GOVINDARAGHAVAN, S., SUCHER, N.J. Epilepsy \& Behavior 52B, 2015, p. 363.

3. ANTAL, D.S., CORICOVAC, D., SOICA, C.M., ARDELEAN, F., PANZARU, I., DANCIU, C., et al. Rev Chim. (Bucharest), 65, no. 9, 2014, p. 1122.

4. JI, S., FATTAHI, A., RAFFEL, N., HOFFMANN, I., BECKMANN, M.W. et al. EurJ Med Res. 22, 2017, p. 50.

5. COZMA, D., KALIFA, J., PESCARIU, S., LIGHEZAN, D., STIUBEI, M. et al. Pace-Pacing and Clinical Electrophysiology 26(1), 2003, p. 436-439. 6. SCANNAPIECO, F.A., CANTOS, A. Periodontology 72(1), 2016, p. 153. 7. GABOR, A., HOSSZU, T., ZAHARIA, C., KOZMA, A., COJOCARIU, A.C. et al. Mat. Plast., 54, no.1, 2017, p. 29-31.

8. XU, R., FAZIO, G.C., MATSUDA, S.P. Phytochemistry 65, 2004, p. 261. 9. LASZCZYK, M.N. Planta Med 75(15), 2009, p. 1549.

10. JAGER, S., TROJ AN, H., KOPP, T., LASZCZYK, M.N., SCHEFFLER, A. Molecules. 14, 2009, p. 2016.

11. MINDA, D., PAVEL, I.Z., BORCAN, F., CORICOVAC, D., PINZARU, I., ANDRICA, F., et al. Rev. Chim. (Bucharest), 66, no.3, 2015, p. 373.

12. PEREIRA, M.C., OLIVEIRA, D.A., HILL, L.E., ZAMBIAZI, R.C., BORGES, C.D., VIZZOTTO, M. et al. Food Chem 240, 2018, p. 396.

13. PAUL, S., BHATTACHARYYA, S.S., BOUJ EDAINI, N., KHUDA-BUKHSH, A.R. Evid Based Complementary Altern Med 2011(Article ID 517204), 2011, 13 pages.

14. PINZARU, I., HEGHES, A., MARTI, D., DEHELEAN, C., CORICOVAC, D., MOACA, A., et al. Rev. Chim.(Bucharest), 69, no.1, 2018, p. 121.

15. UD DIN, S., BAYAT, A. Wound Repair and Regeneration 25(2), 2017, p. 164.

16. DEHELEAN, C.A., SOICA, C., PINZARU, I., CORICOVAC, D., DANCIU, C., PAVEL, l., et al. Food Chem Toxicol 95, 2016, p. 149.

Manuscript received: 18.12 .2018 